\title{
QUALIDADE FISIOLÓGICA E SANITÁRIA DE SEMENTES DE ARROZ COM DIFERENTES GRAUS DE UMIDADE E TRATADAS COM FUNGICIDA ${ }^{1}$
}

\author{
JULIANOZAMBRANO SCHUCH ${ }^{2}$, ORLANDOANTONIO LUCCAFILHO ${ }^{3}$, SILMARTEICHERTPESKE ${ }^{4}$, LUIZMARCELO COSTADUTRA ${ }^{5}$, MIRIAN \\ FERNANDES BRANCÃO ${ }^{6}$, MARIANE D'ÁVILAROSENTHAL $^{7}$
}

\begin{abstract}
RESUMO - O presente estudo teve por objetivo analisar o efeito do tratamento químico, com diferentes concentrações de calda fungicida, sobre a qualidade fisiológica e sanitária das sementes de arroz, durante período de seis meses de armazenamento hermético. Foram utilizadas sementes de arroz, variedades BR-IRGA 410, BRS PELOTA e EMBRAPA 7 TAIM, colhidas na região de Pelotas, RS, na safra 2001/2002. As sementes foram tratadas com o fungicida Carboxin/Thiram, na dose de $300 \mathrm{~mL} .100 \mathrm{~kg}^{-1}$ de sementes e, para a formulação da calda fungicida, foram empregadas doses de 1,2 e 3\% de água em mistura com fungicida. Iguais percentagens de água, sem adição do fungicida, além de uma testemunha, constituíram os sete tratamentos. $\mathrm{O}$ armazenamento foi realizado em garrafas de PVC (tipo “pet”), separadas por tratamento e colocadas no interior de caixas de isopor, durante 180 dias. As sementes foram submetidas aos testes de determinação do grau de umidade, germinação, vigor (frio) e sanidade, em três épocas: no pré-armazenamento (imediatamente após o tratamento), aos 90 e 180 dias. O delineamento experimental utilizado foi blocos completamente casualizados, com três repetições. Os resultados obtidos demonstram que o tratamento de sementes com o fungicida Carboxin/Thiram resultou em aumento da percentagem de germinação, para a avaliação realizada imediatamente após o tratamento, bem como foi eficiente na diminuição da incidência dos principais fungos associados às sementes de arroz. A associação entre graus de umidade e fungicida torna acelerado o processo de deterioração das sementes, armazenadas em ambientes herméticos, podendo ocasionar a morte destas em menos de 180 dias de armazenamento, especialmente quando a umidade for superior a $15 \%$. Com o armazenamento hermético, é possível armazenar sementes por períodos de até 90 dias, com graus de umidade inferiores a $15 \%$ e se o armazenamento for realizado em períodos superiores a 180 dias, os graus de umidade das sementes devem ser inferiores a $13 \%$ para que não ocorra a diminuição da germinação.
\end{abstract}

Termos para indexação: Oryza sativa, sanidade, tratamento de sementes, vigor.

\section{PHYSIOLOGICALAND SANITARY QUALITY OF RICE SEEDS STORED WITH DIFFERENTS SEED MOISTURECONTENTS ANDFUNGICIDE TREATED}

\begin{abstract}
The objective of the present study was to analyze the effect of chemcial treatment, with different concentrations of fungicide dilution, on rice seed physiological and sanitary quality, during a six-month period of hermetic storage. Rice seeds, cvs BR-IRGA410, BRS PELOTA and EMBRAPA 7 TAIM, produced during the 2001/2002 crop year, were treated with Carboxin/Thiram fungicide, with dosage of $300 \mathrm{~mL} .100 \mathrm{~kg}$ of seeds. The fungicide dilution was 1.2 and $3 \%$ water mixed with fungicide. The seeds were stored in PV bottles ("pet" type) and placed inside polystyrene
\end{abstract}

\footnotetext{
${ }^{1}$ Submetido em 28/09/2004. Aceito para publicação em 31/03/2005. Parte da Dissertação de Mestrado em Ciência e Tecnologia de Sementes da Universidade Federal de Pelotas (UFPel), apresentada pelo primeiro autor;

${ }^{2}$ Eng. Agrônomo, Mestre, discente do Doutorado em Ciência e Tecnologia de Sementes, FAEM/UFPel, julianoschuch@bol.com.br;

${ }^{3}$ Eng. Agrônomo, Doutor, professor da FAEM/UFPel, CP 354, CEP 96001970, Pelotas, RS;
}

\footnotetext{
${ }^{4}$ Eng. Agrônomo, PhD, professor da FAEM/UFPel, CP 354, CEP 96001970, Pelotas, RS

${ }^{5}$ Eng. Agrônomo, Doutor, professor do Centro de Ciências Rurais, Faculdade de Agronomia/ UFSM, CEP 97105-900, Santa Maria, RS;

${ }^{6}$ Eng. Agrônoma, Mestre, Doutoranda em Fitossanidade / FAEM/UFPel, Pelotas, RS;

${ }^{7}$ Eng. Agrônoma, Doutora, FAEM/UFPel, Pelotas, RS.
} 
boxes, for 180 days. The seeds were submitted to moisture determination, standard germination, vigor (cold test) and health tests, at three times: in the pre-storage (immediately after the treatment), at 90 and 180 days after treatment. The results indicated that seed treatment with the Carboxin/ Thiram fungicide resulted in higher germination percentage, when the evaluation was made immediately after the treatment and also resulted in the reduction of the main fungi associates on the rice seeds. The interaction between moisture content and fungicide increasedt the deterioration process of the seeds stored under air-tight environments and resulted in complete germination loss, in less than 180 days of storage, especially when seed moisture was above $15 \%$. With air-tight storage, it is possible to store seeds up to 90 days with seed moisture content below $15 \%$ and up tol 180 days when the seeds are stored with less than $13 \%$ moisture content.

Index terms: Oryza sativa, health, seed treatment, vigor.

\section{INTRODUÇÃO}

Uma característica marcante da produção de arroz no Brasil é o crescimento da produtividade paralelamente ao avanço da tecnologia. Atualmente, os produtores colhem cerca de duas vezes mais do que colhiam há trinta anos, devido especialmente aos avanços obtidos com o emprego de novas cultivares e técnicas de manejo do solo e do cultivo. Entre esses avanços, inclui-se o uso de produtos químicos para o controle de doenças, aplicados tanto nas plantas como em sementes.

Em culturas como milho e soja, o tratamento de sementes para inibir a ocorrência de fungos é muito utilizado, já em arroz isto não ocorre na mesma intensidade, apesar da existência de grande número de agentes patogênicos associados às sementes.

Os cuidados que o tratamento de sementes requer, especialmente para não causar danos à própria semente, podem ser uma das razões desta tecnologia ser adotada por reduzido número de produtores. A opção de aplicar o fungicida antes do armazenamento das sementes, ou aplicação e semeadura imediatamente após o tratamento, exige algumas precauções.

Um dos principais motivos que levam o produtor a não realizar o tratamento antecipadamente à semeadura é a impossibilidade de utilizar estas sementes para consumo se, por algum motivo, não forem utilizadas como sementes. Além disso, o tratamento, se inadequadamente realizado, pode causar diminuição da qualidade fisiológica da semente, se esta for armazenada. Isto ocorre em virtude das quantidades de água utilizadas para diluir o produto. Puzzi (1986) e Neergaard (1977) afirmaram que o grau de umidade influencia diretamente a qualidade da semente armazenada, possibilitando o desenvolvimento de fungos, insetos e ácaros.

Nesse sentido, parece que o tratamento das sementes, seguido da semeadura é a melhor opção, pois não haverá efeito latente negativo do fungicida sobre a semente, nem da quantidade de água utilizada. Mas, deve-se atentar ao fato de que a realização da semeadura depende de fatores climáticos, o que pode levar o produtor a tratar suas sementes, mas que seja obrigado a armazená-las da mesma forma, em razão da impossibilidade da entrada das máquinas no campo. Além disso, mesmo não ocorrendo imprevistos climáticos, essas sementes serão armazenadas durante o período de entressafra.

Segundo o estudo realizado por Souza e Peske (1999), são necessários quatro meses para que todas as sementes embaladas em sacos entrem em equilíbrio higroscópico com o ar ambiente. Supõe-se, então, que em uma pilha de 400 sacos, o período normal de armazenamento seja insuficiente para que as sementes localizadas mais internamente na pilha troquem umidade com o ar externo. Isso permite inferir que o interior da pilha seja como uma zona higroscopicamente delimitada. Conseqüentemente, nesta zona, as sementes mantêm seu grau de umidade inicial inalterado durante o período de armazenamento. Em embalagens impermeáveis, as sementes enfrentam limitações similares quanto à troca de umidade com o ar externo registradas por aquelas que estão localizadas no interior de uma pilha de sacos.

Partindo desses pressupostos, o presente estudo teve por objetivo analisar o efeito do tratamento químico, com diferentes concentrações de calda fungicida, sobre a qualidade fisiológica e sanitária das sementes de arroz, durante o período de seis meses de armazenamento, embaladas em recipientes herméticos.

\section{MATERIAL E MÉTODOS}

Para o desenvolvimento deste estudo foram utilizadas sementes de três variedades de arroz irrigado, produzidas na 
região de Pelotas-RS, na safra 2001/2002, BR-IRGA 410 (410), BRS PELOTA (Pelota) e EMBRAPA 7 TAIM (Taim). As duas primeiras possuem casca pilosa e a última, casca lisa.Tal característica foi observada em virtude da possibilidade de melhor fixação do fungicida na semente. As sementes foram colhidas no mês de abril e submetidas ao tratamento químico quatro meses após.

Para cada variedade foram utilizados três lotes, os quais representaram as repetições, com germinação mínima de $80 \%$, pureza física mínima de $98 \%$ e umidade máxima de $14 \%$.

$\mathrm{O}$ tratamento de sementes foi realizado com um produto comercial, composto pela associação dos fungicidas Carboxin, do grupo químico das anilidas de ação sistêmica, e Thiram, do grupo químico do thiocarbamato e ação de contato. A dose utilizada foi de $300 \mathrm{~mL}$ por $100 \mathrm{~kg}$ de sementes, de acordo com as Recomendações Técnicas de 1999.

Para a execução do experimento foram realizados sete tratamentos, nos quais as quantidades de água utilizadas foram baseadas no princípio deste estudo: aumentar a umidade das sementes, associada à utilização de fungicida, a fim de verificar seu comportamento após período de armazenamento. Cada tratamento foi aplicado nos três lotes das variedades BR-IRGA 410, BRS PELOTA e EMBRAPA 7 TAIM.

As sementes foram separadas em porções de $1,2 \mathrm{~kg}$, recebendo os seguintes tratamentos:

T1: Testemunha, porção não-modificada $-0 \%$

T2: Pulverização com $12 \mathrm{~mL}$ de água - 1\%

T3: Pulverização com $12 \mathrm{~mL}$ de solução fungicida $(3,6 \mathrm{~mL}$ de fungicida mais $8,4 \mathrm{~mL}$ de água) $-1 \% \mathrm{~T}$

T4: Pulverização com $24 \mathrm{~mL}$ de água - $2 \%$

T5: Pulverização com $24 \mathrm{~mL}$ de solução fungicida $(3,6 \mathrm{~mL}$ de fungicida mais 20,4mL de água) - 2\% T

T6: Pulverização com $36 \mathrm{~mL}$ de água - 3\%

T7: Pulverização com $36 \mathrm{~mL}$ de solução fungicida $(3,6 \mathrm{~mL}$ de fungicida mais $32,4 \mathrm{~mL}$ de água) - 3\% T

Imediatamente após tratadas, as sementes foram acondicionadas em garrafas PVC de dois litros (tipo "Pet"), e separadas de acordo com o tratamento, em caixas de isopor, onde permaneceram por seis meses. A colocação das sementes em garrafas "Pet" simula o que ocorre no interior das pilhas de sacos, pois se devidamente fechadas, as mudanças do grau de umidade do interior com o ambiente externo inexistem.

Para a avaliação da qualidade fisiológica foram realizados os testes de determinação do grau de umidade, germinação, vigor e sanidade, sendo os três primeiros realizados no Laboratório de Análise de Sementes e o último no Laboratório de Patologia de Sementes, ambos na Faculdade de Agronomia
Eliseu Maciel, da Universidade Federal de Pelotas. O procedimento deu-se em três períodos: no préarmazenamento, aos 90 dias e 180 dias de armazenamento, após o tratamento.

Para a determinação do grau de umidade utilizou-se o método da estufa elétrica a $105{ }^{\circ} \mathrm{C}$, cujo resultado final foi obtido pela média aritmética das percentagens de cada uma das subamostras, retiradas de cada tratamento, conforme Brasil (1992).

Para a realização do teste de germinação foram distribuídas, uniformemente, 50 sementes sob duas folhas de papel mata-borrão, umedecidas com água destilada, na proporção de 2,5 vezes o peso do papel. Em seguida, colocouse outras duas folhas de papel mata-borrão sob as sementes e preparados os rolos. Os rolos foram colocados em germinador a $25 \pm 2{ }^{\circ} \mathrm{C}$. Foram efetuadas duas contagens, aos sete e 14 dias, e a apresentação dos resultados foi feita pela média aritmética das quatro repetições, em números percentuais inteiros (Brasil, 1992).

$\mathrm{O}$ vigor foi estimado pelo teste de frio, utilizando o mesmo procedimento para o teste de germinação realizado, sendo os rolos acondicionados em sacos plásticos, permanecendo a $10^{\circ} \mathrm{C}$ por sete dias. Após esse período, os rolos foram transferidos para germinador regulado à temperatura de $25 \pm$ $2^{\circ} \mathrm{C}$. A apresentação dos resultados foi feita pela média aritmética das quatro amostras, em números percentuais inteiros (Krzyzanowski et al. 1999).

Para o teste de sanidade foi utilizado o método sobre papel filtro. Primeiramente os gerbox foram lavados com solução de hipoclorito de sódio (1\%). Em seguida, foram dispostas duas folhas de papel de filtro em cada gerbox, umedecidas com água destilada até a saturação, onde foram colocadas 25 sementes. As sementes foram incubadas à temperatura de $20 \pm 2^{\circ} \mathrm{C}$, no regime de 12 horas de luz e 12 horas de escuro, com duas lâmpadas de $40 \mathrm{~W}$ de luz fluorescente comum, dispostas sobre os gerbox a $40 \mathrm{~cm}$. Após sete dias cada semente foi examinada separadamente sob microscópio estereoscópico. A identificação foi feita com base na esporulação dos fungos. Foram utilizadas 200 sementes para cada lote (Neergaard, 1977).

Após proceder a leitura, os fungos observados foram divididos em três diferentes grupos: fungos de campo (Fusarium spp., Alternaria spp., Gerlachia sp., Dreschlera spp., Curvularia sp., Phoma sp., Nigrospora sp.); fungos de armazenamento (Aspergillus spp. e Penycillium sp.); outros, aqueles fungos com incidência baixa (Epicoccum sp., Cercospora sp., Rhyzopus sp., Pestalotia sp., Trichoderma 
sp., Chaetomium sp.).

O modelo utilizado para realizar a análise estatística foi o de blocos completamente casualizados, em arranjo fatorial (sete tratamentos e três épocas de avaliação) com três repetições. A comparação de médias foi realizada separadamente para cada cultivar. A análise foi efetuada com o programa para estatística WinStat 2.0 (Machado e Conceição, 2003) e, para a comparação das médias, usou-se o teste de Duncan (5\%). Para análise os dados dos testes de germinação e de frio sofreram transformação no seno. Nas tabelas, são apresentadas as médias originais.

\section{RESULTADOS E DISCUSSÃO}

Nas Tabelas 1, 2 e 3 estão apresentados os graus de umidade das sementes nos diferentes tratamentos, registrados no pré-armazenamento (imediatamente após o tratamento), aos 90 dias e 180 dias de armazenagem.

Ao comparar-se o tratamento das variedades BR-IRGA 410 (Tabela 1) e BRS-PELOTA (Tabela 2), sem adição de água (T1), com as que receberam $1 \%$ (volume/peso) de água ou calda fungicida (T2 e T3), observa-se aumento no grau de umidade de aproximadamente $0,9 \%$. Já as que receberam $2 \%$ (T4 e T5) tiveram acréscimo de $1,8 \%$ e com $3 \%$ (T6 e T7), o aumento foi de $2,5 \%$. Com a variedade EMBRAPA 7 TAIM (Tabela 3), os acréscimos foram menores quando utilizados $1 \%$ (volume/peso) de água ou calda fungicida (T2 e T3), obteve-se $0,7 \%$; a $2 \%$ (T4 e T5), o aumento foi de $1,5 \%$ e com 3\% (T6 e T7), o acréscimo foi de 2,3\%.

Ressalta-se, no entanto, que as sementes da variedade EMBRAPA 7 TAIM utilizadas possuíam umidade inicial de

TABELA 1. Grau de umidade de sementes de arroz, variedade BR-IRGA 410, armazenadas durante 180 dias

\begin{tabular}{lcccc}
\hline \multirow{2}{*}{ Tratamentos } & \multicolumn{3}{c}{ Período de Armazenamento } & \multirow{2}{*}{ C.V. (\%) } \\
\cline { 2 - 5 } & Pré-armazenamento & 90 dias & 180 dias & \\
\hline T1- 0\% & $13,7 \mathrm{Aa}$ & $13,2 \mathrm{Ba}$ & $13,0 \mathrm{Ba}$ & 0,94 \\
T2- $1 \%$ & $14,5 \mathrm{Ab}$ & $14,1 \mathrm{Bb}$ & $13,7 \mathrm{Cb}$ & 1,08 \\
T3- $1 \% \mathrm{~T}^{*}$ & $14,5 \mathrm{Ab}$ & $13,7 \mathrm{Bb}$ & $13,6 \mathrm{Bb}$ & 1,35 \\
$\mathrm{~T} 4-2 \%$ & $15,5 \mathrm{Ac}$ & $14,6 \mathrm{ABc}$ & $14,6 \mathrm{Bc}$ & 1,47 \\
$\mathrm{~T} 5-2 \% \mathrm{~T}^{*}$ & $15,4 \mathrm{Ac}$ & $14,7 \mathrm{Bc}$ & $14,5 \mathrm{Bc}$ & 1,16 \\
$\mathrm{~T} 6-3 \%$ & $16,4 \mathrm{Ad}$ & $16,0 \mathrm{Be}$ & $15,6 \mathrm{Bd}$ & 2,14 \\
T7- 3\% T* & $16,3 \mathrm{Ad}$ & $15,5 \mathrm{Bd}$ & $15,4 \mathrm{Bd}$ & 1,87 \\
\hline C.V. $(\%)$ & 1,43 & 1,87 & 1,23 & \\
\hline
\end{tabular}

- Médias acompanhadas por letras maiúsculas distintas na linha e minúsculas distintas na coluna, diferem entre si, pelo teste de Duncan (5\%).

$\mathrm{T}^{*}=$ sementes tratadas com fungicida.
TABELA2. Grau de umidade de sementes de arroz, variedade BRS PELOTA, armazenadas durante 180 dias

\begin{tabular}{lcccc}
\hline \multirow{2}{*}{ Tratamentos } & \multicolumn{3}{c}{ Período de Armazenamento } & \multirow{2}{*}{ C.V. (\%) } \\
\cline { 2 - 5 } & Pré-armazenamento & 90 dias & 180 dias & \\
\hline T1- $0 \%$ & $13,6 \mathrm{Aa}$ & $13,1 \mathrm{Ba}$ & $12,9 \mathrm{Ba}$ & 1,55 \\
$\mathrm{~T} 2-1 \%$ & $14,6 \mathrm{Ab}$ & $14,1 \mathrm{Bb}$ & $13,7 \mathrm{Bb}$ & 1,58 \\
T3- $1 \% \mathrm{~T}^{*}$ & $14,4 \mathrm{Ab}$ & $13,8 \mathrm{Bb}$ & $13,6 \mathrm{Bb}$ & 1,49 \\
$\mathrm{~T} 4-2 \%$ & $15,2 \mathrm{Ac}$ & $14,8 \mathrm{ABc}$ & $14,6 \mathrm{Bc}$ & 1,45 \\
T5-2\% T* & $15,6 \mathrm{Acd}$ & $14,8 \mathrm{Bc}$ & $14,6 \mathrm{Bc}$ & 0,83 \\
T6- 3\% & $16,2 \mathrm{Ae}$ & $15,7 \mathrm{Bd}$ & $15,2 \mathrm{Cd}$ & 0,60 \\
T7-3\% T* & $15,9 \mathrm{Ade}$ & $15,4 \mathrm{Ad}$ & $15,2 \mathrm{Ad}$ & 3,45 \\
\hline C.V. $(\%)$ & 1,91 & 1,71 & 1,80 & \\
\hline
\end{tabular}

- Médias acompanhadas por letras maiúsculas distintas na linha e minúsculas distintas na coluna, diferem entre si, pelo teste de Duncan (5\%).

$\mathrm{T}^{*}=$ sementes tratadas com fungicida.

TABELA3. Grau de umidade de sementes de arroz, variedade EMBRAPA 7 TAIM, armazenadas durante 180 dias

\begin{tabular}{lcccc}
\hline \multirow{2}{*}{ Tratamentos } & \multicolumn{3}{c}{ Período de Armazenamento } & \multirow{2}{*}{ C.V. (\%) } \\
\cline { 2 - 4 } & Pré-armazenamento & 90 dias & 180 dias & \\
\hline T1- $0 \%$ & $12,8 \mathrm{Aa}$ & $12,4 \mathrm{Ba}$ & $12,3 \mathrm{Ba}$ & 1,16 \\
T2- $1 \%$ & $13,9 \mathrm{Abc}$ & $13,2 \mathrm{Bb}$ & $12,9 \mathrm{Bb}$ & 1,60 \\
T3- $1 \% \mathrm{~T}^{*}$ & $13,5 \mathrm{Ab}$ & $13,0 \mathrm{ABb}$ & $12,8 \mathrm{Bb}$ & 1,93 \\
T4- $2 \%$ & $14,5 \mathrm{Ade}$ & $13,9 \mathrm{Bc}$ & $13,7 \mathrm{Bc}$ & 2,06 \\
T5- $2 \% \mathrm{~T}^{*}$ & $14,1 \mathrm{Acd}$ & $13,8 \mathrm{Ac}$ & $13,7 \mathrm{Ac}$ & 2,75 \\
T6-3\% & $15,3 \mathrm{Af}$ & $14,8 \mathrm{Bd}$ & $14,4 \mathrm{Bd}$ & 1,23 \\
T7-3\% T* & $15,0 \mathrm{Aef}$ & $14,5 \mathrm{Ad}$ & $14,3 \mathrm{Ad}$ & 2,44 \\
\hline C.V. $(\%)$ & 2,28 & 1,77 & 1,82 & \\
\hline
\end{tabular}

- Médias acompanhadas por letras maiúsculas distintas na linha e minúsculas distintas na coluna, diferem entre si, pelo teste de Duncan $(5 \%)$.

$\mathrm{T}^{*}=$ sementes tratadas com fungicida.

$12,8 \%$, enquanto que as demais $13,7 \%$. Este fator esclarece a maior variação nos testes de germinação e vigor da EMBRAPA 7 TAIM em relação às demais.

A partir das Tabelas 1, 2 e 3, constata-se que, entre o pré-armazenamento e os 180 dias, houve decréscimo de 0,4 a $1 \%$ dos teores de água das sementes. Recipientes herméticos, adotados neste trabalho, são utilizados para manter invariável o grau de umidade das sementes durante o período de armazenamento. No entanto, o fato de abrir-se as garrafas para obtenção de amostras de trabalho, a fim de realizar os testes propostos neste estudo, pode justificar a diminuição do grau de umidade ao longo do armazenamento.

Os resultados obtidos nas variedades BR-IRGA 410 (Tabela 4) e BRS PELOTA (Tabela 5), através dos testes de germinação realizados no pré-armazenamento, indicam que as sementes tratadas com fungicida apresentaram 
TABELA 4. Percentagem de plântulas normais obtidas através do teste de germinação de sementes de arroz da variedade BR-IRGA 410, armazenadas durante 180 dias

\begin{tabular}{lcllr}
\hline & \multicolumn{3}{c}{ Período de Armazenamento } & \\
\cline { 2 - 4 } Tratamentos & Pré-armazenamento & $90 \mathrm{dias}$ & $180 \mathrm{dias}$ & C.V. $(\%)$ \\
\hline T1- $\%$ & $91 \mathrm{Abcd}$ & $93 \mathrm{Aa}$ & $58 \mathrm{Ba}$ & 10,58 \\
T2- $1 \%$ & $89 \mathrm{Ad}$ & $91 \mathrm{Aab}$ & $28 \mathrm{Bb}$ & 4,42 \\
$\mathrm{~T} 3-2 \%$ & $90 \mathrm{Acd}$ & $90 \mathrm{Aab}$ & $41 \mathrm{Bab}$ & 18,63 \\
$\mathrm{~T} 4-3 \%$ & $91 \mathrm{Abcd}$ & $89 \mathrm{Aab}$ & $31 \mathrm{Bb}$ & 5,32 \\
$\mathrm{~T} 5-1 \% \mathrm{~T}^{*}$ & $94 \mathrm{Aabc}$ & $88 \mathrm{Bbc}$ & $1 \mathrm{Cc}$ & 2,75 \\
T6-2\% T* & $95 \mathrm{Aa}$ & $85 \mathrm{Bc}$ & $0 \mathrm{Cc}$ & 3,01 \\
T7- $3 \% \mathrm{~T}^{*}$ & $95 \mathrm{Aab}$ & $67 \mathrm{Bd}$ & $0 \mathrm{Cc}$ & 5,91 \\
\hline C.V. $(\%)$ & 3,18 & 3,10 & 36,40 \\
\hline
\end{tabular}

- Médias acompanhadas por letras maiúsculas distintas na linha e minúsculas distintas na coluna, diferem entre si, pelo teste de Duncan (5\%). $\mathrm{T}^{*}=$ sementes tratadas com fungicida.

TABELA 5. Percentagem de plântulas normais obtidas através do teste de germinação de sementes de arroz da variedade BRS PELOTA, armazenadas durante 180 dias

\begin{tabular}{|c|c|c|c|c|}
\hline \multirow{2}{*}{ Tratamentos } & \multicolumn{3}{|c|}{ Período de Armazenamento } & \multirow{2}{*}{ C.V. $(\%)$} \\
\hline & Pré-armazenamento & 90 dias & 180 dias & \\
\hline $\mathrm{T} 1-0 \%$ & $81 \mathrm{Ac}$ & $85 \mathrm{Aa}$ & $67 \mathrm{Ba}$ & 2,57 \\
\hline $\mathrm{T} 2-1 \%$ & $81 \mathrm{Ac}$ & $82 \mathrm{Aab}$ & $56 \mathrm{Ba}$ & 4,65 \\
\hline T3- $2 \%$ & $82 \mathrm{Ac}$ & $84 \mathrm{Aa}$ & $41 \mathrm{Bb}$ & 2,11 \\
\hline T4- 3\% & $81 \mathrm{Ac}$ & $82 \mathrm{Aab}$ & $41 \mathrm{Bb}$ & 3,12 \\
\hline T5- $1 \% \mathrm{~T}^{*}$ & $84 \mathrm{Abc}$ & $88 \mathrm{Aa}$ & $40 \mathrm{Bb}$ & 10,48 \\
\hline $\mathrm{T} 6-2 \% \mathrm{~T}^{*}$ & $89 \mathrm{Aa}$ & $81 \mathrm{Bab}$ & $0 \mathrm{Cc}$ & 3,24 \\
\hline $\mathrm{T} 7-3 \% \mathrm{~T} *$ & $88 \mathrm{Aab}$ & $78 \mathrm{Bb}$ & $0 \mathrm{Cc}$ & 2,49 \\
\hline C.V. $(\%)$ & 3,16 & 2,48 & 12,27 & \\
\hline
\end{tabular}

- Médias acompanhadas por letras maiúsculas distintas na linha e, minúsculas distintas na coluna, diferem entre si, pelo teste de Duncan $(5 \%)$.

$\mathrm{T}^{*}=$ sementes tratadas com fungicida.

percentagem de germinação superior às não-tratadas. Ao observar a variedade EMBRAPA 7 TAIM (Tabela 6), constatase menor variação entre os resultados, mas comparando-se entre tratamentos com mesmo grau de umidade, as tratadas, apresentam percentagens de germinação superiores às nãotratadas. Estas diferenças podem ser atribuídas à menor incidência de fungos nas sementes tratadas. A eficiência de fungicidas na erradicação de fungos, sejam eles patogênicos ou não, como o efeito nocivo de fungos sobre a qualidade das sementes, foi comprovada por vários pesquisadores (Neergaard, 1977; Ribeiro, 1996; Machado, 2000; Lucca Filho, 2001; Pereira, 2002).

Após 90 dias de armazenamento, observa-se que as sementes tratadas (T3, T5 e T7) começaram a diminuir seus percentuais germinativos (Tabelas 4, 5 e 6), igualando-se às não-tratadas (T2, T4 e T6) e até mesmo, apresentando menor germinação em relação a estas. É importante ressaltar que os tratamentos com 3\% T (T7), independentemente da variedade, apresentaram os menores resultados de germinação, diferindo dos demais tratamentos, embora as sementes destes tratamentos tenham apresentado, no pré-armazenamento, as mais altas porcentagens de germinação. Estes resultados sugerem a existência de efeito nocivo da alta umidade associada ao tratamento com fungicida. Entre as não-tratadas, constatase não haver diferença entre as leituras do pré-armazenamento e dos 90 dias.

Nas sementes tratadas ocorreu redução nos índices de germinação entre as duas avaliações, à exceção dos tratamentos BRS PELOTA 1\% T (T3), EMBRAPA 7 TAIM 1\% T (T3) e EMBRAPA 7 TAIM 2\% T (T5). Nota-se que as reduções mais significativas na percentagem de germinação foram observadas nos tratamentos com maior volume de calda, indicando que em sementes armazenadas com baixo conteúdo de umidade, o possível efeito nocivo do fungicida não ocorre.

Aos 180 dias, pode-se observar que sementes não-tratadas (T2, T4 e T6) apresentaram maior percentagem de germinação do que as tratadas (T3, T5 e T7). Ressalta-se que em sementes sem nenhum tipo de tratamento (T1), a redução da qualidade foi menos acentuada. Destaca-se que os tratamentos apresentaram, após 180 dias de armazenamento, percentagens de germinação inferiores a $60 \%$. Tal resposta não foi observada na variedade BRS PELOTA 0\% (T1) e também na EMBRAPA 7 TAIM, para a qual, sementes com aumento de $1 \%$ de umidade (T2 e T3), mantiveram germinação de aproximadamente $80 \%$ após seis meses de armazenamento. Isso pode ser explicado pelo fato de as sementes destas variedades apresentarem umidade inferior a $13 \%$, sendo que na variedade EMBRAPA 7 TAIM este valor foi mantido

TABELA 6. Percentagem de plântulas normais obtidas através do teste de germinação de sementes de arroz da variedade EMBRAPA7TAIM, armazenadas durante 180 dias

\begin{tabular}{ccccc}
\hline \multirow{2}{*}{ Tratamentos } & \multicolumn{3}{c}{ Período de Armazenamento } & \multirow{2}{*}{ C.V. (\%) } \\
\cline { 2 - 4 } & Pré-armazenamento & 90 dias & 180 dias & \\
\hline T1- 0\% & $85 \mathrm{Bb}$ & $91 \mathrm{Aa}$ & $85 \mathrm{Ba}$ & 2,61 \\
$\mathrm{~T} 2-1 \%$ & $85 \mathrm{Ab}$ & $92 \mathrm{Aa}$ & $73 \mathrm{Ba}$ & 6,09 \\
$\mathrm{~T} 3-2 \%$ & $88 \mathrm{Aab}$ & $90 \mathrm{Aa}$ & $73 \mathrm{Ba}$ & 7,61 \\
$\mathrm{~T} 4-3 \%$ & $89 \mathrm{Aab}$ & $90 \mathrm{Aa}$ & $31 \mathrm{Bb}$ & 7,61 \\
$\mathrm{~T} 5-1 \% \mathrm{~T}^{*}$ & $91 \mathrm{Aa}$ & $93 \mathrm{Aa}$ & $79 \mathrm{Aa}$ & 8,49 \\
T6- $2 \% \mathrm{~T}^{*}$ & $89 \mathrm{Aab}$ & $92 \mathrm{Aa}$ & $1 \mathrm{Bc}$ & 5,76 \\
T7-3\% T* & $91 \mathrm{Aa}$ & $85 \mathrm{Bb}$ & $0 \mathrm{Cc}$ & 3,38 \\
\hline C.V. $(\%)$ & 3,21 & 2,55 & 13,50 & \\
\hline
\end{tabular}

- Médias acompanhadas por letras maiúsculas distintas na linha e minúsculas distintas na coluna, diferem entre si, pelo teste de Duncan (5\%).

$\mathrm{T}^{*}=$ sementes tratadas com fungicida. 
durante todo o período de armazenamento.

Os testes de frio (Tabelas 7, 8 e 9) realizados no préarmazenamento indicaram que as sementes tratadas com fungicida (T3, T5 e T7) apresentaram maior vigor em relação às não-tratadas (T1, T2, T4 e T6), resultado confirmado em estudo realizado por Zorato e Henning (2001), ao determinarem que sementes de soja tratadas e armazenadas por 30 dias apresentaram melhor resposta em relação às nãotratadas.

Os resultados obtidos no pré-armazenamento indicam que as sementes do tratamento 3\% T (T7), nas três variedades, foram as que apresentaram maior vigor; já as com 3\% (T6), foram as de menor vigor. Isso pode ser explicado pelo fato de se ter, neste tratamento (T7), melhor distribuição do fungicida e melhor recobrimento das sementes, o que contribui-se para uma maior eficiência do fungicida na erradicação de fungos, permitindo que a semente expresse seu potencial de qualidade. A eficiência de fungicidas na erradicação de fungos e melhoria da qualidade das sementes é enfatizada por vários autores, como Menten (1991), Ribeiro (1996) e Pereira (2002).

Aos 90 dias de armazenamento, observa-se que as sementes, independentemente do tratamento, apresentaram níveis de vigor superior a 70\%, exceção a BR-IRGA 410 3\% T (T7). No entanto, comparando-se estes níveis de vigor, com o vigor obtido no pré-armazenamento, observa-se que as sementes da variedade BR-IRGA 410 tratadas (T3, T5 e T7) tiveram redução significativa no vigor após 90 dias de armazenamento, embora não tenham diferido das sementes não tratadas. Para a variedade BRS PELOTA, reduções mais significativas ocorreram nas sementes tratadas com maior volume de calda (T5 e T7), enquanto que para variedade EMBRAPA 7 TAIM, somente nas sementes tratadas com 3\%

TABELA 7. Percentagem de plântulas normais obtidas através do teste de frio, de sementes de arroz da variedade BR-IRGA 410, armazenadas durante 180 dias

\begin{tabular}{ccccc}
\hline \multirow{2}{*}{ Tratamentos } & \multicolumn{3}{c}{ Período de Armazenamento } & \multirow{2}{*}{ C.V. (\%) } \\
\cline { 2 - 4 } & Pré-armazenamento & $90 \mathrm{dias}$ & $180 \mathrm{dias}$ & \\
\hline T1- 0\% & $87 \mathrm{Abcd}$ & $85 \mathrm{Aa}$ & $56 \mathrm{Ba}$ & 7,44 \\
T2- $1 \%$ & $85 \mathrm{Acd}$ & $82 \mathrm{Aa}$ & $8 \mathrm{Bc}$ & 9,82 \\
T3- 2\% & $83 \mathrm{Ad}$ & $86 \mathrm{Aa}$ & $17 \mathrm{Bb}$ & 6,11 \\
T4- 3\% & $76 \mathrm{Be}$ & $86 \mathrm{Aa}$ & $23 \mathrm{Cb}$ & 4,34 \\
T5- 1\%T* & $90 \mathrm{Abc}$ & $82 \mathrm{Ba}$ & $0 \mathrm{Cd}$ & 4,70 \\
T6- 2\% T* & $91 \mathrm{Ab}$ & $83 \mathrm{Ba}$ & $0 \mathrm{Cd}$ & 3,05 \\
T7- 3\% T* & $95 \mathrm{Aa}$ & $62 \mathrm{Bb}$ & $0 \mathrm{Cd}$ & 4,05 \\
\hline C.V. $(\%)$ & 3,30 & 4,09 & 22,98 & \\
\hline
\end{tabular}

- Médias acompanhadas por letras maiúsculas distintas na linha e minúsculas distintas na coluna, diferem entre si, pelo teste de Duncan (5\%). $\mathrm{T}^{*}=$ sementes tratadas com fungicida.
TABELA 8. Percentagem de plântulas normais obtidas através do teste de frio, de sementes de arroz da variedade BRS PELOTA, armazenadas durante 180 dias

\begin{tabular}{lcllr}
\hline \multirow{2}{*}{ Tratamentos } & \multicolumn{3}{c}{ Período de Armazenamento } & \multirow{2}{*}{ C.V. (\%) } \\
\cline { 2 - 5 } & Pré-armazenamento & $90 \mathrm{dias}$ & $180 \mathrm{dias}$ & \\
\hline T1-A 0\% & $73 \mathrm{Ab}$ & $75 \mathrm{Abc}$ & $71 \mathrm{Aa}$ & 5,66 \\
T2- $1 \%$ & $75 \mathrm{Ab}$ & $74 \mathrm{Ac}$ & $55 \mathrm{Bb}$ & 6,19 \\
T3- $2 \%$ & $75 \mathrm{Ab}$ & $74 \mathrm{Abc}$ & $43 \mathrm{Bbc}$ & 4,22 \\
T4- 3\% & $71 \mathrm{Ab}$ & $79 \mathrm{Aabc}$ & $33 \mathrm{Bc}$ & 11,33 \\
T5- $1 \% \mathrm{~T}^{*}$ & $84 \mathrm{Aa}$ & $83 \mathrm{Aa}$ & $30 \mathrm{Bc}$ & 5,18 \\
T6- $2 \% \mathrm{~T}^{*}$ & $84 \mathrm{Aa}$ & $80 \mathrm{Bab}$ & $0 \mathrm{Cd}$ & 3,40 \\
T7- 3\% T* & $86 \mathrm{Aa}$ & $79 \mathrm{Babc}$ & $0 \mathrm{Cd}$ & 2,29 \\
\hline C.V. $(\%)$ & 3,39 & 2,94 & 15,42 & \\
\hline
\end{tabular}

- Médias acompanhadas por letras maiúsculas distintas na linha e minúsculas distintas na coluna, diferem entre si, pelo teste de Duncan $(5 \%)$.

$\mathrm{T}^{*}=$ sementes tratadas com fungicida.

TABELA 9. Percentagem de plântulas normais obtidas através do teste de frio, de sementes de arroz da variedade EMBRAPA 7 TAIM, armazenadas durante 180 dias

\begin{tabular}{ccccr}
\hline \multirow{2}{*}{ Tratamentos } & \multicolumn{3}{c}{ Período de Armazenamento } & \multirow{2}{*}{ C.V. (\%) } \\
\cline { 2 - 4 } & Pré-armazenamento & $90 \mathrm{dias}$ & $180 \mathrm{dias}$ & \\
\hline $\mathrm{T} 1-0 \%$ & $82 \mathrm{Abc}$ & $84 \mathrm{Ab}$ & $82 \mathrm{Aa}$ & 3,56 \\
$\mathrm{~T} 2-1 \%$ & $82 \mathrm{Abc}$ & $82 \mathrm{Ab}$ & $56 \mathrm{Bb}$ & 8,24 \\
$\mathrm{~T} 3-2 \%$ & $81 \mathrm{Abc}$ & $82 \mathrm{Ab}$ & $58 \mathrm{Bb}$ & 3,72 \\
$\mathrm{~T} 4-3 \%$ & $77 \mathrm{Ac}$ & $82 \mathrm{Ab}$ & $26 \mathrm{Bc}$ & 17,93 \\
T5- $1 \% \mathrm{~T}^{*}$ & $82 \mathrm{Abc}$ & $91 \mathrm{Aa}$ & $39 \mathrm{Bbc}$ & 14,28 \\
T6- $2 \% \mathrm{~T}^{*}$ & $88 \mathrm{Aab}$ & $88 \mathrm{Aa}$ & $0 \mathrm{Bd}$ & 3,84 \\
T7- 3\% T* & $94 \mathrm{Aa}$ & $79 \mathrm{Bb}$ & $0 \mathrm{Cd}$ & 2,44 \\
\hline C.V. $(\%)$ & 3,21 & 2,93 & 24,02 \\
\hline
\end{tabular}

- Médias acompanhadas por letras maiúsculas distintas na linha e minúsculas distintas na coluna, diferem entre si, pelo teste de Duncan $(5 \%)$.

$\mathrm{T}^{*}=$ sementes tratadas com fungicida.

T (T7) a redução de vigor foi significativa, em relação ao vigor inicial.

Independentemente da variedade, as maiores reduções de vigor foram observadas no tratamento $3 \% \mathrm{~T}$ (T7). À semelhança do observado no teste de germinação, maiores reduções de vigor foram observadas nas sementes que receberam maior volume de calda por ocasião do tratamento. Isso indica que sementes com grau de umidade superior a $15 \%$ têm sua armazenabilidade comprometida, a partir de três meses de armazenamento.

Aos 180 dias de armazenamento, pode-se observar severa redução do vigor das sementes, especialmente daquelas tratadas com maior volume de calda fungicida (T5 e T7), confirmando os resultados obtidos no teste de germinação. Com exceção das sementes da variedade EMBRAPA 7 TAIM não tratadas (T1), todas as demais, por possuírem grau de umidade superior a 13\%, não suportaram um período de 180 dias de armazenamento. 
A variabilidade observada na microflora das sementes, por ocasião da avaliação do teste de sanidade, permitiu classificar os fungos em três grupos distintos: fungos de campo (Fusarium spp., Alternaria spp., Gerlachia sp., Dreschlera spp., Curvularia sp., Phoma sp., Nigrospora sp.); fungos de armazenamento (Aspergillus spp. e Penicillium sp.), representando os de relevância para este estudo; e outros, demais fungos (demais gêneros de fungos de patogenicidade relativa e fungos contaminantes), que não possuem destacada importância para a cultura do arroz.

Na Tabela 10, encontram-se especificados os fungos de campo e de armazenamento encontrados nos testes iniciais, em seus respectivos lotes, em cada uma das variedades. Naquele período as sementes não haviam sido tratadas e nem armazenadas, proporcionando constatar quais fungos estavam presentes previamente nas variedades. É relevante destacar a maior incidência de cada um dos gêneros de fungos nas classificações utilizadas, pois estes podem ter respostas diferentes quando submetidos ao tratamento e armazenamento.

Nesta Tabela 10, constatou-se que as variedades BRIRGA 410 e EMBRAPA 7 TAIM apresentaram alta incidência dos fungos de campo dos gêneros Gerlachia sp. e Fusarium spp. e baixo nível dos demais. Já a variedade BRS PELOTA teve alta incidência de Fusarium spp., além de registrar diversos fungos de outros gêneros, em quantidades superiores a das demais variedades. Em relação aos fungos de armazenamento, a incidência foi baixa nas três variedades.

Os resultados obtidos nos testes de sanidade (Tabelas 11,12 e 13), mostram que o tratamento com fungicida foi eficiente na redução da incidência de fungos em todas as variedades, sendo capaz de reduzir o potencial de inóculo de $60 \%$ para menos de $20 \%$.

Nos tratamentos em que foram utilizados maiores volumes de calda fungicida foi observada maior eficiência no controle dos fungos, em relação aos tratamentos com menor volume de calda, explicado pela melhor distribuição do fungicida em maiores volumes de calda, além de melhor cobertura das sementes. Ressalta-se que nenhum dos tratamentos foi capaz de erradicar todos gêneros de fungos.

Outra constatação foi a redução da incidência de fungos de campo durante o armazenamento. Trabalhos realizados com soja indicam que a maioria dos fungos de campo perdem viabilidade ao longo do período de armazenamento, uns de forma mais acentuada que outros. Exemplo clássico é a redução completa da viabilidade de Phomopsis sp., após oito meses de armazenamento (Lucca Filho, 1981). Essa redução na incidência de fungos de campo durante o armazenamento das sementes também pode ser explicada pelo fato do mesmo

TABELA 10. Percentagem de fungos, após teste de sanidade em sementes de arroz, variedades BR-IRGA 410, BRS PELOTA e EMBRAPA 7 TAIM, referente à infestação inicial antes da realização dos tratamentos e do armazenamento

\begin{tabular}{lcccccccc}
\hline \multirow{2}{*}{ Variedades } & \multicolumn{7}{c}{ Gêneros de fungos (\%) } \\
\cline { 2 - 8 } & Fus. & Gerl. & Dresch. & Alter. & Curv. & Pho. & Pen./Asp. & Outros \\
\hline 410 & 20 & 28 & 2 & 1 & 1 & 2 & 1 & 1 \\
PELOTA & 40 & 2 & 5 & 5 & 8 & 4 & 1 & 2 \\
TAIM & 19 & 40 & 2 & 1 & 1 & 1 & 0 & 1 \\
\hline
\end{tabular}

Fus. = Fusarium spp.; Gerl. = Gerlachia sp.; Dresch. = Dreschlera spp.; Alter. =Alternaria spp.; Curv. = Curvularia sp.; Pho. $=$ Phoma sp.; Pen./Asp. $=$ Penicillium sp. e Aspergillus spp.

TABELA 11. Percentagem dos fungos de campo (C), armazenamento (A) e outros $(\mathrm{O})$, no período de armazenamento de 180 dias, após realização do teste de sanidade de sementes de arroz da variedade BR-IRGA 410

\begin{tabular}{|c|c|c|c|c|c|c|c|c|c|}
\hline \multirow{3}{*}{ Tratamentos } & \multicolumn{9}{|c|}{ Período de Armazenamento } \\
\hline & \multicolumn{3}{|c|}{ Pré-armazenamento } & \multicolumn{3}{|c|}{90 dias } & \multicolumn{3}{|c|}{180 dias } \\
\hline & $\mathrm{C}(\%)$ & $\mathrm{A}(\%)$ & $\mathrm{O}(\%)$ & $\mathrm{C}(\%)$ & $\mathrm{A}(\%)$ & $\mathrm{O}(\%)$ & $\mathrm{C}(\%)$ & $\mathrm{A}(\%)$ & $\mathrm{O}(\%)$ \\
\hline T1- $0 \%$ & 53 & 1 & 1 & 38 & 3 & 1 & 7 & 1 & 2 \\
\hline $\mathrm{T} 2-1 \%$ & 45 & 1 & 1 & 30 & 1 & 1 & 5 & 0 & 1 \\
\hline T3- $1 \% \mathrm{~T}^{*}$ & 13 & 1 & 1 & 2 & 1 & 1 & 0 & 1 & 2 \\
\hline $\mathrm{T} 4-2 \%$ & 51 & 2 & 0 & 22 & 1 & 0 & 1 & 1 & 1 \\
\hline $\mathrm{T} 5-2 \% \mathrm{~T}^{*}$ & 8 & 1 & 1 & 1 & 0 & 1 & 0 & 0 & 1 \\
\hline T6 3\% & 55 & 4 & 1 & 5 & 0 & 1 & 1 & 3 & 1 \\
\hline $\mathrm{T} 7-3 \% \mathrm{~T}^{*}$ & 3 & 1 & 1 & 0 & 0 & 0 & 1 & 1 & 1 \\
\hline
\end{tabular}

$\mathrm{T}^{*}=$ sementes tratadas com fungicida. 
TABELA 12. Percentagem dos fungos de campo (C), armazenamento (A) e outros $(\mathrm{O})$, no período de armazenamento de 180 dias, após realização do teste de sanidade de sementes de arroz da variedade BRS PELOTA

\begin{tabular}{|c|c|c|c|c|c|c|c|c|c|}
\hline \multirow{3}{*}{ Tratamentos } & \multicolumn{9}{|c|}{ Período de Armazenamento } \\
\hline & \multicolumn{3}{|c|}{ Pré-armazenamento } & \multicolumn{3}{|c|}{90 dias } & \multicolumn{3}{|c|}{180 dias } \\
\hline & $\mathrm{C}(\%)$ & $\mathrm{A}(\%)$ & $\mathrm{O}(\%)$ & $\mathrm{C}(\%)$ & $\mathrm{A}(\%)$ & $\mathrm{O}(\%)$ & $\mathrm{C}(\%)$ & A (\%) & $\mathrm{O}(\%)$ \\
\hline T1-0\% & 65 & 1 & 2 & 53 & 1 & 2 & 18 & 0 & 1 \\
\hline $\mathrm{T} 2-1 \%$ & 54 & 1 & 2 & 48 & 1 & 1 & 14 & 1 & 0 \\
\hline $\mathrm{T} 3-1 \% \mathrm{~T}^{*}$ & 27 & 1 & 2 & 9 & 1 & 0 & 2 & 0 & 1 \\
\hline T4- $2 \%$ & 62 & 3 & 2 & 36 & 0 & 1 & 6 & 0 & 1 \\
\hline $\mathrm{T} 5-2 \% \mathrm{~T} *$ & 10 & 1 & 1 & 2 & 0 & 1 & 0 & 0 & 0 \\
\hline T6- 3\% & 65 & 1 & 5 & 20 & 1 & 2 & 2 & 0 & 1 \\
\hline $\mathrm{T} 7-3 \% \mathrm{~T}^{*}$ & 5 & 4 & 5 & 0 & 0 & 0 & 1 & 0 & 0 \\
\hline
\end{tabular}

$\mathrm{T}^{*}=$ sementes tratadas com fungicida.

TABELA 13. Percentagem dos fungos de campo (C), armazenamento (A) e outros $(\mathrm{O})$, no período de armazenamento de 180 dias, após realização do teste de sanidade de sementes de arroz da variedade EMBRAPA 7 TAIM

\begin{tabular}{|c|c|c|c|c|c|c|c|c|c|}
\hline \multirow{3}{*}{ Tratamentos } & \multicolumn{9}{|c|}{ Período de Armazenamento } \\
\hline & \multicolumn{3}{|c|}{ Pré-armazenamento } & \multicolumn{3}{|c|}{90 dias } & \multicolumn{3}{|c|}{180 dias } \\
\hline & $\mathrm{C}(\%)$ & $\mathrm{A}()(\%)$ & $\mathrm{O}(\%)$ & $\mathrm{C}(\%)$ & $\mathrm{A}(\%)$ & $\mathrm{O}(\%)$ & $\mathrm{C}(\%)$ & $\mathrm{A}(\%)$ & $\mathrm{O}(\%)$ \\
\hline T1- $0 \%$ & 63 & 0 & 1 & 52 & 0 & 0 & 13 & 1 & 0 \\
\hline $\mathrm{T} 2-1 \%$ & 61 & 0 & 0 & 42 & 0 & 1 & 7 & 1 & 1 \\
\hline $\mathrm{T} 3-1 \% \mathrm{~T}^{*}$ & 16 & 1 & 0 & 4 & 0 & 0 & 0 & 0 & 0 \\
\hline T4- $2 \%$ & 61 & 0 & 1 & 41 & 1 & 0 & 4 & 1 & 0 \\
\hline T5- $2 \% \mathrm{~T}^{*}$ & 8 & 0 & 0 & 2 & 0 & 1 & 1 & 0 & 0 \\
\hline T6- 3\% & 69 & 1 & 0 & 23 & 0 & 0 & 2 & 4 & 0 \\
\hline $\mathrm{T} 7-3 \% \mathrm{~T}^{*}$ & 5 & 0 & 0 & 0 & 1 & 0 & 0 & 0 & 1 \\
\hline
\end{tabular}

$\mathrm{T}^{*}=$ sementes tratadas com fungicida.

ter ocorrido sob condições herméticas (Elias, 2002; Caldasso, 1998; Forlin, 1991). Em relação aos fungos de armazenamento, não houve aumento em nenhum dos sete tratamentos. Isto pode ser explicado pelo fato da contaminação inicial das sementes ser muito baixa (máximo de $4 \%$ ) e pelo armazenamento ter sido realizado sob condições herméticas, as quais impedem a contaminação das sementes por esporos dos fungos presentes no ambiente.

A existência de pilosidade na casca das sementes resulta na maior retenção de fungicida, comparativamente as sementes de casca lisa. Esta maior retenção pode-se expressar através de anormalidades de plântulas, tanto em testes de laboratório como na emergência em condições de campo. Nas variedades BR-IRGA 410 e BRS PELOTA, de superfície pilosa, não se observou efeito sobre a aderência do fungicida na superfície das sementes, em relação à variedade EMBRAPA 7 TAIM, de casca lisa. Isto porque não foram observadas diferenças quanto a menor incidência de fungos, bem como em relação à qualidade fisiológica das sementes, cujas variações no número de plântulas anormais não diferiram, assim não se observaram variações entre estas cultivares, decorrentes de uma possível toxicidade, devido a uma maior retenção de fungicida pela pilosidade existente na lema e na pálea das sementes de arroz.

\section{CONCLUSÕES}

O tratamento de sementes com o fungicida Carboxin/ Thiram, na dose de $300 \mathrm{~mL}$ por $100 \mathrm{~kg}$ de sementes resultou em aumento da percentagem de germinação para a avaliação realizada imediatamente após tratamento.

O tratamento de sementes com o fungicida Carboxin/ Thiram reduz a incidência dos fungos Fusarium spp., Alternaria spp., Gerlachia sp., Dreschlera spp., Curvularia sp., Phoma sp. associados às sementes de arroz.

A associação de alta umidade com fungicida torna acelerado o processo de deterioração das sementes armazenadas em ambientes herméticos, podendo ocasionar a morte destas em menos de 180 dias de armazenamento, principalmente quando a umidade for superior a $15 \%$.

Com o armazenamento hermético, é possível armazenar 
sementes por períodos de até 90 dias com teores de umidade inferiores a $15 \%$ e se o armazenamento for realizado em períodos superiores a 180 dias, os graus de umidade das sementes devem ser inferiores a $13 \%$, para que não ocorra diminuição da germinação.

\section{REFERÊNCIAS}

BRASIL, Ministério da Agricultura e Reforma Agrária. Regras para análise de sementes. Brasília: SNDA/DNDV/CLAV, 1992.365 p.

CALDASSO, L.H.S. Uso de ácidos orgânicos e hermeticidade no armazenamento de grãos de milho. Pelotas: Universidade Federal de Pelotas, 1998. 70p.

ELIAS, M.C. Armazenamento e conservação de grãos em médias e pequenas escalas. Pelotas: UFPEL/FAEM: Pólo de Inovação Tecnológica em Alimentos da Região Sul do Rio Grande do Sul: COREDE-SUL, 2002.218p.

FORLIN, F.J. Conservabilidade de grãos de sorgo granífero [Sorghum bicolor (L.)Moench], armazenados com umidade de colheita e incorporação de ácidos orgânicos, nos sistemas convencional, granel e hermético. Pelotas: Universidade Federal de Pelotas, 1991. 110p.

KRZYZANOWSKI, F.C.; VIEIRA, R.D.; FRANÇA NETO, J.B. Vigor de sementes: conceitos e testes. Londrina: ABRATES, 1999. 218p.

LUCCA FILHO, O.A. Efeitos do tratamento com fungicidas sobre a qualidade das sementes de soja (Glycine max (L.) Merrill) armazenadas sob condições ambientais. Pelotas: Universidade Federal de Pelotas, 1981.

LUCCA FILHO, O.A. Patologia de sementes. In. Curso de especialização por tutoria à distância. Brasília: ABEAS/UFPel/ FAEM, 2001. 54p.

MACHADO, A.A.; CONCEIÇÃO, A.R. WinStat, sistema para análise estatística para Windows. Versão 2.0. Pelotas: UFPel/ NIA. 2003.

MACHADO, J.C. Tratamento de sementes no controle de doenças. Lavras: LAPS/UFLA/FAEPE, 2000. 138p.

MENTEN, J.O.M. Patógenos em sementes: detecção, danos e controle químico. Piracicaba: ESALQ/FEALQ, 1991. 321p.

NEERGAARD, P. Incubation tests. In: Seed Pathology. London: Macmillan Press, 1977. 839p.

PEREIRA, J.L.A. Patologia de sementes de arroz. Disponível em $<$ http://orbita.starmedia.com/ fitopatologia/patoarroz.htm $>$ Acesso em 25 mai. 2003.

PUZZI, D. Abastecimento e armazenagem de grãos. Campinas: Instituto Campineiro de Ensino Agrícola, 1986. 603 p.

RIBEIRO, A.S. Tratamento de sementes com fungicidas. Revista Anual de Patologia de Plantas, Passo Fundo, v. 4, 1996.

SOUZA, F.V.; PESKE, S.T. Absorção de água pela semente de soja e de milho durante o armazenamento. Revista Brasileira de Sementes, Brasília, v. 21, n. 2, p.78-83, 1999.

ZORATO, M.F.; HENNING, A.A. Influência de tratamentos fungicidas antecipados, aplicados em diferentes épocas de armazenamento, sobre a qualidade de sementes de soja. Revista Brasileira de Sementes, Brasília, v. 23, n. 2, p. 236-244, 2001.

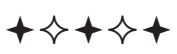

